\title{
Biographical disruption and factors facilitating overcoming it
}

\author{
Maruta Pranka \\ Rīga Stradinsš University, Latvia
}

\begin{abstract}
In the paper the concept "biographical disruption" is interpreted as a process that includes significant changes in the course of an individual's life and biography as the perception and interpretation of the life course. As the central concept of the paper, biographical disruption is analyzed as having been brought about by an inherited heightened risk of breast cancer or ovarian cancer. The paper has examined the influence of the inherited breast cancer genes BRCA1 and BRCA2 on the development of biographical disruption. The empirical research data used for the study were obtained from the interdisciplinary research project "Creation of a new interdisciplinary research team to investigate breast cancer and to increase the efficacy of therapy and the patient's quality of life" (agreement No. 2009/0230/1DP/1.1.1.2.0/09/APIA/VIAA/070). In studying and analyzing the possibilities of overcoming a biographical disruption, the conclusion is that this depends on the individual's own biographical work, or narrative reconstruction and various types of social support.
\end{abstract}

Key words: biographical disruption, biographical work, social support.

\section{Introduction}

The concept of biographical disruption describes the influence of a significant, sudden event or events on the course of an individual's life that cardinally changes its direction and plans. Significant changes that affect an individual are experienced both objectively and explained and interpreted subjectively in a person's biography.

The paper analyses individual and social factors that provide individuals with favourable conditions to facilitate a successful overcoming of biographical disruption. The term "biographical disruption" was coined in 1982 by British sociologist Michael Bury [1] to describe the experience of chronic illness and the way in which a life-threatening illness breaks an individual's social and cultural experience by threatening his or her self-identity. Bury concluded that chronic illness influences in an individual's biography:

1) habits and perception of life change;

2) relationship between the ill person and those in his or her social network changes some relationships are lost, others change;

3) resources - time, energy, finances, family, friends - must be mobilized [1].

In analyzing the experience of biographical disruption, Bury used Anthony Giddens' concept of "critical situation", which Giddens had applied to disruptions of a social nature, assuming that significant events in a person's biography had the same sort of influence [2]. The concept "biographical disruption" is interpreted as a process that includes significant changes in the course of an individual's life and his or her biography as well as perception and interpretation 
of the life course. Biographical disruption is analyzed as the process brought about by a "turning point" [3] or "fateful moment" [4] that is the basis for subsequent changes in a person's identity. Fateful moments put in motion a process in which the individual may become completely different person. Fateful moments can potentially provide experience opportunities as well as develop self-identity and future action.

Historical experience with radical social transformations and today's dynamic changes in the social sphere create a risk of biographical disruption in people's biographies. Biographical disruption can also be caused by critical situations of a personal nature during a person's lifetime, leading to a risk of stigmatization for individuals as well as whole social groups. Knowledge of the process of biographical disruption, as well as the ways of overcoming it and identifying possibilities, can become a foundation upon which individuals can overcome a biographical disruption and facilitate their individual and social well-being.

\section{Material and methods}

The paper analyzes data from empirical study of serious chronic illness or heightened risk thereof as the cause of biographical disruption. The data were obtained when the author worked on the interdisciplinary research project "Creation of a new interdisciplinary research team to investigate breast cancer and to increase the efficiency of therapy and the patient's quality of life" (agreement No. 2009/0230/1DP/1.1.1.2.0/09/APIA/VIAA/070) conducted in Oncology institute of Riga Stradinš̌ university.

The analysis of biographical disruption in the empirical study uses in-depth biographical interviews with women $(N=15)$ who were carriers of the inherited gene $B R C A l$ and/or $B R C A 2$. The development of guidelines for the in-depth interviews was based on data from a quantitative questionnaire of breast cancer patients following a mastectomy $(n=300)$ in the frame of the mentioned project. The sample was created from the national database at the Oncology Institute of Riga Stradinšs University, which contains histories of inherited breast cancer cases and the results of genetic tests for BRCA mutations. The selection of women included in the empirical study consisted of women who in the past four years have been identified as carriers of the inherited $B R C A$ gene mutation. In order to have respondents from various socio-demographic strata as well as varying levels of general health, a focused selection from the Oncology Institute's database was done. The selection included carriers of the inherited $B R C A 1$ or BRCA2 gene, four of whom were healthy, seven had had breast cancer, two had had ovarian cancer and two had had both ovarian and breast cancer. The youngest of the women was 26 years old during the study, and the oldest was 64 years old. Five of the respondents had close relatives with diagnosed the BRCA1 or $B R C A 2$ breast cancer gene. The remaining respondents had no information about the existence of inherited cancer genes among their close relatives because such tests had not been done.

When interviewing both healthy and sick (treated) carriers of BRCA1 and BRCA2, an interpretation of the respondents' situations was revealed through personal narratives. The interview guidelines included the following themes: 1) previous experience and information about breast cancer and a characterization of the family's experience; 2) people with whom the respondent discusses issues of illness, inherited genes and heightened risk of illness; 3) whether and how the respondent's personality, thinking and lifestyle had been influenced as a result of receiving information about inherited genes and heightened risk of illness; 4) a subjective explanation of the origin of the illness; 5) whether and how the respondent's social relationships had changed; 6) availability of various resources and opportunities to use the respondent's own individual capital; 7) how the respondent manages living with the biographical disruption situation; 8) the ways of overcoming biographical disruption. 
The interviews were conducted by researchers involved in the study including the author.

In the paper abbreviations are used: Brc-breast cancer; Ov - ovarian cancer; (54) - age of respondent.

\section{Results}

Alongside the identified mutual characteristic features, another aspect of the biographical disruptions is that these disruptions have been influenced by the individual's belonging to a certain family. In the case of illness or the heightened risk of illness it is the family through which the inherited breast cancer gene is passed down.

Anselm Strauss analyzed biographical disruption as a process brought about by a "turning point" [5] stressing that the process of change is always put in motion by a single point, namely, the turning point. This turning point is initially identified as the critical event that provokes the person to admit that "I'm not the same as I was before, as I was used to being" and is accompanied by surprise, shock, bitterness, confusion, tension and/or a feeling of defeat in his or her experience of self [3:95]. Correspondingly to this situation, the individual searches for a new self "to fill the new experience with meaning and overcome the disruption brought about by this turning point that has led to a transformation of identity" [7:99].

Even though biographical disruption can be caused by various events and conditions and each individual experiences it differently, biographical disruptions nevertheless have mutual characteristic features:

1. Identity break or transformation, when the previous identity is interrupted and a new identity is created in its place that corresponds to the new situation, new individual feelings and also new external needs. This is a traumatic process, because it leads to a shocking awareness of the break between the past and the future.

2. Changes in social relationships take place; the changes taking place during the process of biographical disruption that affect the central actor in the process also apply to members of his or her closest social relationships. These members are either delegated new functions or they take up these new functions themselves by offering various types of social support. In some cases social relationships are terminated.

3. The need to mobilize resources in a situation of biographical disruption establishes the need to involve experts (good experts!).

4. Changes in the availability and use of capital and resources available to the individual. Even though the individual's need for various resources increases during biographical disruption, his or her access to such resources, as well as his or her use of individual capital, decreases or even becomes impossible.

The influence of the inherited gene manifests itself as:

1) the individual's own illness,

2) heightened risk of becoming ill.

In both situations the biographical disruption is a cumulative process that includes not only the actual event, namely, the illness or the receiving of information about the inherited gene. But also the experience with the process and results of this illness within close social relations, with whom there are genetically links. The study shows that biographical disruption took place also in the cases when the illness affects not the individual herself but the close relation. The fear about mother or sister, the fatality feelings promotes radical changes of individual identity; these changes are increased by the information of the inherited cancer gene. The majority of interviewed women admits that they "were ready" to have the illness since their 
mothers were ill with cancer. The information about their inherited gene was accepted by them as the approval of the misgiving.

Anna's (50, Ov) mother died of ovarian cancer at the age of 56. Mother's sister also had the same disease. Anna tells that the most painful feelings were connected with mother's illness. "I was so wounded with mother's illness. I could not sleep, could not talk when I got to know the diagnosis. I was depressed absolutely. Yes, I was stressed when I got my diagnosis and the information about the gene. But I thought about my children, that they were so young. No, I was not shocked about myself. It was much easier."

Individuals with a heightened risk of illness tend to have one of two attitudes towards their diagnoses: preparation and denial. Denial as a disallowing of the negative consequences and negative thoughts as well as a fear of positive genetic test results spares the emotions, but it is nevertheless an insufficient evaluation of the risk of illness. The positive aspect of learning one's genetic inheritance is an elevation of self-esteem through the process of identity transformation and heightened attention to health-promoting activities in order to lessen the risk of illness for oneself and other family members. Health care providers ought to emphasize these positive aspects and communicate them to individuals with heightened risk of illness.

The aspect as activation of motherhood identity feelings must be stressed essentially for women with both adult and little children. Women feel themselves responsible for the children's health, because they pass the genetic risk to the next generation $[6,7]$. Women with little children are afraid of not having enough time to bring up their children.

By helping to their mother during breast or ovarian cancer women had prepared themselves to similar future. 40 years old Karīna (Brc) remembers her mother's and grandmother's illness and says:

"I knew everything and I wrote it down. It was necessary for my mother, but I knew somewhere in my inner space - yes I did it also for myself".

Biographical disruption caused by the illness integrates other essential aspect of identity change - change of body identity, change of visual image, pains and suffering. Williams [8] calls this process body alienation or betrayal of the body.

Sarma $(44, \mathrm{Brc})$ in the interview stresses the emotional suffering after the breast amputation. She relates the breath with woman's body identity and the loss of the breath is perceived by her as identity trauma, the loss of woman's identity. Though she has a very understanding and loving partner she feels herself as defective in his eyes. In the cases of illness the body is the uppermost in the individual and social identity. Awareness of the physical problems is before the changes in social relations. The biological facts become social facts because they correspond to the physical essence of the individual.

For the healthy persons with inherited gene the positive gene test arouses changes in individual and social identity without changes of body identity. The changes are caused by the previous life experience and information. The perception of biographical disruption is connected with the contextual situation. Aina (42, healthy) was shocked by the positive gene test results. She was actively looking for different kinds of cancer risk prevention till her son's sudden death. After that she became depressive and apathetic regarding her health. But the birth of her grandchild returned her to the interest in her health.

In studying and analyzing the possibilities of overcoming a biographical disruption, it could be concluded that this depends on the individual's own biographical work or narrative reconstruction [9] and various types of social support. The author of the paper refers to A. Strauss, who, albeit writing about a heavy, long-term illness, describes biographical work as either returning to at least an approximation of one's previous life or restructuring one's life completely. Biographical work serves the actor's biography by including a review, preservation, repair and transformation of it [1]. Such a return to life through the process of 
biographical work can also be attributed to individuals who have experienced a biographical disruption due to social change.

During the process of biographic work performed in cases of biographical disruption, the individual tries to connect the previous identity with the new identity that has arisen during the process if biographical disruption.

In case of a disease or an increased risk of disease an individual changes the view of the future and pursues answers to the questions regarding his/her new relations with the world, and conducts a biographical work, where the understanding of the disease and interpretation of its onset represent an important component. Generally the explanation incorporating several factors of causes of the disease can be observed. Each case is individual; however, the types of subjective explanations of the cause of the disease can be divided into thematic groups:

1. Mental causality, which explains the onset of the disease by various emotional experiences.

2. Views based upon everyday understanding of woman's life full of hardships in the modern society and gender interrelations.

3. A mystified view explaining the disease by the finger of God.

4. The criticism of health care and health experts includes opinions regarding unsatisfactory quality of health care and preventive measures, as well as negative evaluation of attitude of medical professionals (intention and overwork of physicians).

5. Outer factors: work with chemical substances, chemical contamination caused by convenience products, sunbathing; Chernobyl accident; new technologies; heavy physical injuries.

6. Biomedical explanation.

None of the interviews contains univocal explanation of the cause of the disease. They express interpretations of personal experience, knowledge, assumptions and doubts, and health care specialists' explanations.

The second kind of overcoming biographical disruption includes various forms of social support, which facilitates a return to one's previous life or a coming to terms with one's new situation. The use and interpretation of social support concept is becoming increasingly interdisciplinary. In Western industrialized cultures, social support is linked with social integration and understanding that social involvement always also means social support. In sociology, social support resources are considered to be derived from social networks. The task of social support is to amortize and decrease the negative influence on individuals of shocking, traumatic events by helping the individual to adapt socially. The availability of social support and the option to use various types of such support and resources are essential and meaningful factors not only for the health of the individual but also his or her well-being in general. A lack of social support can lead to social exclusion, even marginalization.

Various forms of social support, which facilitates a return to one's previous life or a coming to terms with one's new situation, play an important role in overcoming biographical disruption. Social support focuses on the interaction between individuals and encompasses mainly 4 kinds [12]:

- emotional,

- instrumental,

- informative,

- evaluative. 
Emotional support is received by care, compassion, and understanding in close relationships [13].

Instrumental support is a practical everyday assistance - making meals, support in ensuring hygiene and tidiness, financial help. Instrumental or emotional support, sympathy, or understanding is perceived positively; however, this way of attitude at the same time enhances a gap between former and present life. An individual realizes that people see him/her as an ill person rather than a former one. This situation correlates with the concept of stigma analyzed by Erving Goffman [10] and the situation where an individual feels discredited. The stigmatized individual accepts that his/her difference is publicly known or even evident.

Evaluative support is the situation analysis, provision of recommendations and advice, encouragement in the field of health care, mostly received from specialists in a specific area, as well as other social support resources. All types of support are necessary to minimize the threat to identity caused and endangered by the disease [14], as well as to help in creation of a new identity or to support preservation of the former one, thus facilitating overriding the biographical gap.

Informative support is communication of knowledge and advice regarding the disease and healing.

Alternative support methods should be also mentioned. The mystified causes mentioned in the analysis of the explanations of the roots of the disease, according to the author, also influence personal activity in the ways of spiritual quests which compensate limitations of other types of support.

Important functions of social support, especially within the aspect of evaluation and information, are provided by internet portals, social networks, and internet contacts to receive evaluating, informative, and emotional support. Contacts with other patients provide realization of similar fate and common problems, which can be characterized as a certain understanding of a collective identity. The necessity for an emotional support, especially in younger females, is associated with their external, bodily identity changes, and the support provided by the partners is especially highly appreciated in this aspect. Communication on recovery and positive results of prevention should be mentioned as a special type of support.

It could be stressed that the different kinds of social support are not separated strongly. All of them are very important and necessary to reduce the threats to the identity. Biographical disruption establishes the need to involve experts and resources; at the same time, it also means a decrease or loss of different kinds of capital and the opportunities for using such capitals. Social support of various kinds facilitates a return to the previous life or the satisfactory adaptation of the individual to the new situation. In cases of biographical disruption, the most significant social support is given by members of the closest relationships (generally, the family), in this case the social roles of the family members change and their emotional tension increases. A difficult and chronic illness can create biographical disruption not only for the patients but also for those persons close to them. Therefore, the whole family needs social support. Social support positively influences the preservation or reconstruction of identity and individual well-being as well as lessens the traumatic nature of the biographical disruption.

If there is a deficit of social support provided by professional experts and health care specialists (support that covers informative, evaluative and emotional aspects), people look for mystified explanations and support - identified it as non-traditional support. Such support, however, may provide inadequate social support that does not promote improvement of health. A need for experts who can provide professional and comprehensive social support is identified in the narratives. 
In order for a person to accept and live with an illness or heightened risk of illness, respondents' strategies include the conviction that a healthy lifestyle, decreased stress and regular health check-ups avert the risk of falling ill and lengthen one's survival.

The support provided by experts and informal social networking in the process of biographical disruption is seen as not always sufficient and relevant. There has been identified the need for the availability of such social support that would combine informative and emotional support and that would be offered by an experts having a professional knowledge on the disease or an increased risk of it.

\section{Conclusions}

1. Biographical disruption as a broad concept encompassing individual and social aspects describes a process introduced by a fateful moment and can be analyzed in the context of a lifetime.

2. The biographical disruption caused by the inherited gene is associated with the study of the family context. This means belonging to a family with a certain genetic code.

3. Biographical disruption is a cumulative process of a traumatic nature; its main characteristics are: identity transformation, changes in social relationships, the need for the involvement of experts and resources in order to overcome the disruption, even though an individual's need for various resources increases during a biographical disruption, the accessibility to them as well as the use of the capitals decreases or is lost altogether.

4. Biographical disruption can be overcome if the individual receives social support and performs biographical work, which is the individual's interpretive survey of the course of the lifetime within the interaction between its individual and social aspects. Biographical work is healing in its attempt to unite the previous identity with the new identity that has emerged during the biographical disruption process.

5. During the biographical work process the origin and cause of the illness are explained ambiguously; the origin of the illness is based both on biomedical factors as well as other factors - external or environmental, social, mental and mystified factors.

6. Social support facilitates a return to the previous life or the satisfactory adaptation of the individual to the new situation. Social support positively influences the preservation or reconstruction of identity and individual well-being as well as lessens the traumatic nature of the biographical disruption and it is an important factor in averting the risk of the individual's marginalization. If there is a deficit of social support provided by professional experts and health care specialists (support that covers informative, evaluative and emotional aspects), people look for mystified explanations and support which may provide inadequate social support that does not promote improvement of health.

7. The most significant social support is given by members of the closest social relationships. Due to illness the social roles of the family members change and their emotional tension increases. It can create biographical disruption not only for the patient but also for the close persons. Therefore, the whole family needs social support. As of yet, little research has been done in this area.

The author of the paper thanks to all the respondents of the research for their honesty and sympathy in the process of interviewing. Much thanks for the consultations and advice to Ritma Rungule, Dr. sc. soc. Associated Professor at Riga Stradiņš University and Edvīns Miklaševičs, Dr. biol., Professor at Riga Stradiņš University. 


\section{References}

[1] M. Bury, Sociology of Health and Illness 4(2), 167-182 (1982)

[2] A. Giddens, Central Problems in Social Theory (University of California Press, London, Macmillan, Berkeley, 1979)

[3] A.L. Strauss, Mirrors and Masks: The Search for Identity (Transaction Publishers: New Brunswick, 2007)

[4] A. Giddens, Modernity and Self-identity: Self and Society in the Late Modern Age (Stanford University Press, Stanford, 1991)

[5] T.D. Boldt, Migration biography and ethnic identity: on the discontinuity of biographical experience and how tuning points affect the ethnicisation of identity. edited by K. Hackstaff, F. Kupferberg, C. Negroni, Biography and Turning Points in Europe and America (University of Bristol, UK, The Policy Press, 2012), pp. 93-124

[6] R. Hendrick, R. Smith, C. Smart, J. Nat. Cancer Inst. 1997(22), 87-92 (1997)

[7] L.C. Hartmann, T.A. Sellers, D.J. Schaid, et al., J. Nat. Cancer Inst. 93(21), 1633-1637

[8] S.J. Williams, Sociology of Health \& Illness 22(1), 40-67. Available also in: http://www. aafesp.org.br/biblioteca/AtencaoSaude/Chronic_illness_ derscore interruption.pdf (2000)

[9] G. Williams, Sociology of Health and Illness 6(2), 175-200 (1984)

[10] E. Goffman, Stigma: Notes on the Management of Spoiled Identity (Simon and Schuster, New York, 1963)

[11] J. Corbin, A.L. Strauss, Unending Work and Care: Managing Chronic Illness at Home (Jossey-Bass, San Francisco, 1988)

[12] L.F. Berkman, T. Glass, I. Brissette, T.E. Seeman, Soc. Sci. Med. 51(6), 843-857 (2000)

[13] P. Thoits, J. Health Soc. Behav., 53-79

[14] J. Lugton, J. Adv. Nursing 25(6) 1107-1313 (1997) 